\title{
Fractional condensation of pyrolysis vapors produced from Nordic feedstocks in cyclone pyrolysis
}

Ann-Christine Johansson ${ }^{* 1}{ }^{1}$, Kristiina lisa ${ }^{2}$, Linda Sandström ${ }^{1}$, Haoxi Ben ${ }^{2}$, Heidi Pilath ${ }^{2}$, Henrik Wiinikka ${ }^{1}$, Olov G. W. Öhrman ${ }^{1}$

${ }^{1}$ SP Energy Technology Center AB, Box 726, SE-941 28 Piteå, Sweden

${ }^{2}$ National Renewable Energy Laboratory, 15013 Denver West Parkway, Golden, Colorado 80401, United States

*Corresponding author Tel: +46105166173

E-mail address: ann-christine.johansson@sp.se

(C) 2016. This manuscript version is made available under the Elsevier user license http://www.elsevier.com/open-access/userlicense/1.0/ 


\section{Abstract}

Pyrolysis oil is a complex mixture of different chemical compounds with a wide range of molecular weights and boiling points. Due to its complexity, an efficient fractionation of the oil may be a more promising approach of producing liquid fuels and chemicals than treating the whole oil. In this work a sampling system based on fractional condensation was attached to a cyclone pyrolysis pilot plant to enable separation of the produced pyrolysis vapors into five oil fractions. The sampling system was composed of cyclonic condensers and coalescing filters arranged in series. The objective was to characterize the oil fractions produced from three different Nordic feedstocks and suggest possible applications. The oil fractions were thoroughly characterized using several analytical techniques including water content; elemental composition; heating value, and chemical compound group analysis using solvent fractionation, quantitative ${ }^{13} \mathrm{C}$ NMR and ${ }^{1} \mathrm{H}$ NMR and GC $\times$ GC - TOFMS. The results show that the oil fractions significantly differ from each other both in chemical and physical properties. The first fractions and the fraction composed of aerosols were highly viscous and contained larger energyrich compounds of mainly lignin-derived material. The middle fraction contained medium-size compounds with relatively high concentration of water, sugars, alcohols, hydrocarbonyls and acids and finally the last fraction contained smaller molecules such as water, aldehydes, ketones and acids. However, the properties of the respective fractions seem independent on the studied feedstock types, i.e. the respective fractions produced from different feedstock are rather similar. This promotes the possibility to vary the feedstock depending on availability while retaining the oil properties. Possible applications of the five fractions vary from oil for combustion and extraction of the pyrolytic lignin in the early fractions to extraction of sugars from the early and middle fractions, and extraction of acids and aldehydes in the later fractions. 


\section{Keywords}

Fractional condensation; pyrolysis; cyclone pyrolysis; Nordic feedstock; oil characterization 


\section{Introduction}

Pyrolysis oil, also known as bio-oil and pyrolysis liquid, is a complex mixture of different compounds including water, carboxylic acids, aldehydes, ketones, furfurals, sugar-like material and lignin-derived compounds with a wide range of molecular weights and boiling points $[1,2]$. Some of these compounds are directly related to undesired properties such as high oxygen and water contents, corrosiveness, incompatibility with conventional fuels, aging during storage, heating values less than half that of mineral oils and tendencies to polymerize when heated [3]. Consequently, upgrading is necessary before the oil can be used in more sophisticated applications such as production of liquid transportation fuel.

A number of upgrading technologies, such as catalytic cracking (vapor phase upgrading), catalytic hydrotreatment, catalytic hydro-cracking, processing in supercritical fluids, solvent addition, emulsification and steam reforming [2-5], have been shown to improve the oil properties by foremost reducing the oxygen content and improving the storage stability. The two main technologies for reducing the oxygen content are catalytic hydrotreatment and catalytic cracking [6]. These technologies can significantly improve the properties of the oil but the main drawback is low liquid yield, which makes the processes economically unattractive $[3,4]$. Besides upgrading of the oil to improve the fuel properties, oil fractions can be used for further chemical extraction. Examples of chemicals of interest are phenols used in the resin industry [7,8], volatile acids such as acetic acid [9], carbonyl groups for use as biodegradable slow-release nitrogen fertilizers [10], glycolaldehyde for use in the food flavoring industry [11] and sugars for further upgrading to glucose, which is of interest for fermentation to ethanol or production of other valuable compounds $[9,12]$.

Since pyrolysis oil is very complex with many different compound groups, an efficient fractionation of pyrolysis oil may be a more promising approach of producing liquid fuels and chemicals compared to 
treating the whole oil $[9,13,14]$. Different fractionation concepts have been studied, such as phase separation of the oil by water addition $[1,15]$, controlling the water content by varying the temperature in the condenser $[15,16]$, molecular distillation [17] and fractional condensation $[9,18-21]$. Fractional condensation has received increasing attention for separation of pyrolysis oil components into useful fractions directly in the liquid recovery process. The pyrolysis vapor/gas exiting the fast pyrolysis reactor is passed through a series of condensers maintained at different, gradually decreasing temperatures to enable the collection of each liquid fraction. Pollard et al. [20] studied the fractionation of pyrolysis oil by condensing the vapors in a series of alternating pairs of shell and tube heat exchangers and electrostatic precipitators. Heat exchangers were used to recover the vapors from the gases whereas electrostatic precipitators were used to recover the aerosols. With this type of liquid recovery system, the compounds were separated according to their dew points. Most of the lignin-derived material and sugar-like compounds were recovered in the first and second stages whereas water and acids were condensed in the last stage. Rover et al. [19] continued the work with the same experimental equipment and in their study the aim was to maximize the yield of some desired products, primarily cellulose-derived levoglucosan and lignin-derived phenolic oligomers, by varying the pyrolysis temperature. However, the results showed that the temperature has in general a small effect on the yield of specific chemical constituents in the pyrolysis oil or their distribution across the fractions. Westerhof et al. [9] tried to control the composition and quality of the oil fractions by varying both the temperature in the reactor and the condenser. The results showed that at decreased reactor temperature significantly lower amounts of mid-boilers and heavy compounds are released from the feed. The vapors were condensed using two countercurrent spray columns and an intensive cooler in series. The temperature in the first condenser was varied which enabled varying the composition of the different fractions. The oil fractions were analyzed using a complex analytical scheme to obtain differences in the content of individual compounds. Westerhof et al. [9] suggested that extraction of for example acetic acid and sugars, which 
can be of interest for fermentation and sugar industry, is possible from the different fractions. The first fraction had low water content and was not as acidic as the total oil which makes it more suitable for further refining to produce transportation fuels and chemicals, while the second fraction could be further upgraded by aqueous-phase reforming and gasification in supercritical water.

The economic feasibility varies depending on the chemicals produced from the pyrolysis process. A techno-economic study based on the fractionation system developed at lowa State University indicated that producing biochemicals (i.e. bio-asphalt, bio-cement and dextrose) and hydrocarbons (i.e. hydrocarbon aromatics and olefins) together with biofuels could be more competitive than producing biofuels alone [22].

The ablative cyclone based pyrolysis process $[23,24]$ has shown to be a suitable pyrolysis technology especially for low grade fuels $[25,26]$. In the current contribution, a sampling system based on fractional condensation was attached to the ablative cyclone pilot plant described by Wiinikka et al. [23] enabling production of oil fractions with different chemical and physical properties. The novelty in this study compared to previous fractional condensation studies $[9,19-20]$ is that three different feedstocks have been studied in this work which enables investigation of the influence of feedstock types on the properties of the different oil fractions. The condensation system also differs from those in the literature by configuration (number, order, and type of condensers and aerosol collectors, which affects the composition of the fractions. The aim of this work was to physically and chemically characterize the five oil fractions obtained in the fractional condensation sampling system for pyrolysis of three types of Nordic biomass feedstocks. The studied feedstocks were two forest feedstocks (stem wood and forest residue) and one agricultural feedstock (short rotation willow). The objective was to increase the understanding of fractional condensation, to compare the different feedstocks, and to suggest possible applications for the collected oil fractions. Fractional condensation can be used independent of used 
pyrolysis technology which means that results received using this kind of system can be regarded as generic.

\section{Experimental}

\subsection{Fractional condensation system}

The fractional condensation system was connected to a $20 \mathrm{~kg} \mathrm{~h}^{-1}$ cyclone pyrolysis plant earlier described by Wiinikka et al. [23]. Some operating conditions of the pilot plant during these tests can be seen in Table 1. More information about the pyrolysis experiment and product yield can be found in Sandström et al. [26]. A small part (approximately $6 \%$ or $50 \mathrm{Ndm}^{3} \mathrm{~min}^{-1}$ ) of the hot gas after the cyclone reactor is withdrawn from the pyrolysis pilot plant to the fractional condensation system. In the fractional condensation system, five oil fractions are collected, see Figure 1. The first three fractions of oil are condensed in a series of three jacketed stainless steel cyclones. The condenser cyclones are constructed of $360 \mathrm{~mm}$ long polished stainless pipes with an inner diameter of $40.5 \mathrm{~mm}$ and a volume of about 0.5 $\mathrm{dm}^{3}$. The cut off diameter in the cyclones was roughly estimated according to "Muschelknautz method" to $25 \mu \mathrm{m}$ in the first cyclone, $14 \mu \mathrm{m}$ in the second cyclone and $13 \mu \mathrm{m}$ in the third cyclone. This means that the aerosols, which have a diameter of around $2 \mu \mathrm{m}$ [23], were not collected in the cyclones. The cyclones are jacketed with another stainless steel pipe with an inner diameter of $66 \mathrm{~mm}$. The temperatures of the cyclones are controlled by circulating temperature-controlled water in the outer jacket. Water at $80^{\circ} \mathrm{C}$ is used in the first cyclone, water at $60{ }^{\circ} \mathrm{C}$ in the second cyclone and cold water with a temperature of approximately $4{ }^{\circ} \mathrm{C}$ in the third cyclone. The temperature of the gas is measured and recorded continuously using K-types thermocouples (with a diameter of $1 \mathrm{~mm}$ ) at several positions in the fractional condensation system, denoted T1 - T5. Uninsulated glass bottles under each cyclone are used to collect the oil fractions, denoted fraction $1-3$. The fourth oil fraction is collected using two 
coalescing filters (Parker Zander GL3ZL) each with a volume of $0.5 \mathrm{dm}^{3}$ to primarily collect aerosols larger than $0.01 \mu \mathrm{m}$. Most of the oil trapped in the coalescing filters (denoted fraction 4 ) is collected in a glass bottle placed under the first filter, only small volumes of oil is collected in the second filter and not practicable to extract. The gas is further cooled in a cold trap using carbon dioxide ice and ethanol, and the oil fraction which condenses in this step is denoted fraction 5. Any remaining oil aerosols in the gas are thereafter collected in a glass wool filter, before the gas passes through the vacuum pump and flowmeter and exits to the exhaust. The vapor residence times in the condensers and coalescing filters were estimated to be approximately $0.6 \mathrm{~s}$ based on plug flow assumption.

Prior to the experiments the pyrolysis plant and the fractional condensation system were heated using hot nitrogen gas to obtain an inert atmosphere and avoid condensation of oil on cold surfaces. The pyrolysis oil fractions were collected at the completion of the trials and refrigerated until analysis to minimize chemical reactions.

The observed gas temperatures in the fractional condensation system were rather constant during the experiments. The temperatures were about $388 \pm 15{ }^{\circ} \mathrm{C}(\mathrm{T} 1)$ before entering the fractional condensation system, $258 \pm 15^{\circ} \mathrm{C}(\mathrm{T} 2)$ after the first condenser, $156 \pm 10^{\circ} \mathrm{C}(\mathrm{T} 3)$ after the second condenser, $70 \pm 1{ }^{\circ} \mathrm{C}$ (T4) after the third condenser and below $11 \pm 1{ }^{\circ} \mathrm{C}$ (T5) after the cold trap. The location of the last thermocouple was not close to the cold trap and the gas temperature inside the cold trap was therefore most likely lower than the measured temperature.

\subsection{Feedstocks}

In this investigation three Nordic feedstocks were used: two forest feedstocks (stem wood and forest residue) and one agricultural feedstock (short rotation willow, Salix). The origin and the composition of the feedstocks are described more in detail elsewhere [25]. The stem wood originated from wood pellets 
and consisted of $70-80 \mathrm{wt} \%$ sawdust from pine and the rest from spruce. The forest residue was stored (brown) and consisted of approximately $67 \mathrm{wt} \%$ pine, $30 \mathrm{wt} \%$ spruce and $3 \mathrm{wt} \%$ birch and aspen. Both of the forest feedstocks were grown in northern Sweden, in the province of Norrbotten. The short rotation coppice crop (SRC), willow (Salix) specie Tora, was grown in south of Sweden, in the province of Skåne.

The feedstocks were milled and sieved before entering the pyrolyzer. The milling was performed in a granulator (Rapid granulator) and in a hammer mill (Mafa EU-4B) and particles passing through a 0.75 $\mathrm{mm}$ sieve were used in the study. The particle size distributions of the feedstocks were determined using a sieve shaker (Fritsch, Analysette 3). Most of the particles were in the range $250-500 \mu \mathrm{m}$ and 91 wt $\%$ were smaller than $500 \mu \mathrm{m}$.

Proximate, ultimate and chemical analysis results of the feedstocks are shown in Table 2 . The analyses were performed by certified chemical laboratories; the ultimate analyses and the analyses of heating value were performed by Belab $A B$ (Sweden) while the proximate and inorganic analyses were performed by ALS Scandinavia Luleå (Sweden) and the chemical composition by MoRe Research Scandinavia (Sweden). Results from the proximate analyses show that stem wood differs some from the other feedstocks. Stem wood has a higher amount of volatiles and lower ash residues, while the concentrations in the other feedstocks were rather similar. The forest feedstocks (stem wood and forest residues) have slightly higher carbon contents and lower oxygen contents and therefore also higher heating values compared to the willow. This can be correlated to the higher amount of lignin in the forest feedstocks [27], see Table 2 .

\subsection{Experimental conditions}

All the equipment in the fractional condensation system was independently weighed before and after each run to include all produced oil when using stem wood as feedstock which enabled a correct mass balance over the system. In the runs with the other feedstock all equipment except the cyclones were 
weighed before and after the experiments, i.e. the oil adhered to the walls of the cyclones was not accounted for, which resulted in the weights of fractions 1 to 3 being somewhat underestimated for the test using willow and forest residue. A comparison of the oil yield calculated from the pilot plant's collection system and the fractional condensation system gives an indication of how much oil is trapped on the walls of the cyclones, see Table 3. If assumed that the oil yield is the same in both the collection systems, than in total about $7 \mathrm{wt} \%$ (54 g) of the oil is trapped in the three cyclones when willow was used as feedstock and about 9 wt \% (44 g) when forest residue is used. It is therefore difficult to draw conclusions from the distribution of the fractions for willow and forest residue but the concentrations in the different fractions can, however, be discussed.

\subsection{Analysis of pyrolysis oil fractions}

Five fractions of oil were obtained from each feedstock and they were characterized using traditional analysis methods to determine the water content, acidity, homogeneity, elemental composition, heating value and chemical compound groups by solvent fractionation. The five oil fractions produced from stem wood were additionally analyzed for carbonyl concentrations, molecular weight distribution and chemical compound groups using quantitative ${ }^{13} \mathrm{C}$ NMR and ${ }^{1} \mathrm{H} N \mathrm{NMR}$ and GC $\times \mathrm{GC}-\mathrm{TOFMS}$. The GC $\times$ GCTOFMS was used instead of a GCMS to obtain better separation and identification of pyrolysis oil compounds. More detailed descriptions of the analysis methods used are given below:

- The homogeneity of the oils after mixing was studied by optical microscopy using a Zeiss Stemi 2000-C.

- The water content of the liquids was determined by volumetric Karl-Fischer titration according to ASTM E203 using a Mettler Toledo T50 M titrator. The titrant was Hydranal Composite 5K and 
the solvent was Hydranal Working Medium K, which were chosen in order to prevent problems associated with ketones and aldehydes. Each sample was analyzed in duplicate.

- The pyrolysis oil fractions were categorized into chemical compound groups according to the solvent fractionation scheme developed at VTT [1]. In the method, the oil is divided into water soluble and water insoluble compounds. The water soluble compounds are further separated into ether solubles (ES), which include aldehydes, ketones, acids, alcohols and lignin monomers, and ether insolubles (EIS), which include anhydrosugars, anhydrooligomers and hydroxy acids $(C<10)[1]$. The water insoluble compounds are further divided into dichloromethane solubles, which include low molecular mass (LMM) lignin and extractives, and dichloromethane insolubles, which consist of high molecular mass (HMM) lignin and solids. The pyrolysis oil, the water insoluble compounds, the ether insoluble compounds and the dichloromethane insoluble compounds were weighed, while the amounts of the other compounds were calculated by difference. The water soluble is calculated by subtracting the water insoluble material from the pyrolysis oil, the ether soluble material (ES) by subtracting the ether insoluble material (EIS) from the water soluble material and finally the dichloromethane soluble by subtracting the dichloromethane insoluble material from the water insoluble material. Each sample was analyzed in duplicate.

- The acidity of the oil was measured by analyzing the total acid number, TAN, according to ASTM D664. Potentiometric titration with a Mettler Toledo T50 M titrator was performed. The inflection point closest to the meter reading corresponding to the $\mathrm{pH} 11$ was used to calculate the acid number. Each sample was analyzed in duplicate.

- The analysis of heating value and the ultimate analysis were performed according to standard methods (ASTM D240 and ASTM D5291) by Karlshamns Kraft (Karlshamn, Sweden). Oxygen content was determined by difference. 
- Carbonyl concentrations were measured by potentiometric titration according to a modified Zakas/Feix method [28]. Samples of oil were mixed with dimethylsulfoxide (DMSO) and hydroxylamine hydrochloride $\left(\mathrm{NH}_{2} \mathrm{OH} . \mathrm{HCl}\right)$ and triethanolamine (TEA) solutions in ethanol, and heated to $80^{\circ} \mathrm{C}$ for 2 hours. The samples were titrated against standardized $\mathrm{HCl}$ by $\mathrm{pH}$ titration with equivalence point occurring around pH 3.5. Each sample was analyzed in triplicate.

- Quantitative ${ }^{13} \mathrm{C}$ NMR and ${ }^{1} \mathrm{H}$ NMR analyses were performed using a Bruker Avance 400 spectrometer. The pyrolysis oils $(\sim 250 \mu \mathrm{l})$ were dissolved in DMSO-d6 $(250 \mu \mathrm{l})$ with $5 \mathrm{mg} \mathrm{mL}^{-1}$ chromium (III) acetylacetonate $\left(\mathrm{Cr}(\mathrm{acac}) 3\right.$ ) as relax reagent. ${ }^{13} \mathrm{C}$ NMR spectra were acquired with inverse gated coupling, recycle delay of $8 \mathrm{~s}$ and $90^{\circ}$ pulse angle. ${ }^{1} \mathrm{H}-\mathrm{NMR}$ spectra were acquired at room temperature using standard $90^{\circ}$ angle, $10 \mathrm{~s}$ pulse delay, and 64 scans. The ${ }^{13} \mathrm{C}$ NMR assignments were made according to Ben and Ragauskas [29] and are given in Table S5. The assignment ranges for ${ }^{1} \mathrm{H}$ NMR are shown in Table S6.

- GC x GC - TOFMS analysis was performed in a LECO Pegasus GCXGC-TOF system. Four replicate samples of each oil were prepared by dissolving approximately $20 \mathrm{mg}$ of oil in $1.00 \mathrm{~mL}$ of acetonitrile. An internal standard (2-fluoro-1,1'-biphenyl) was added to each sample to monitor the reproducibility of the GCxGC-TOFMS injection. The primary column was $10 \mathrm{~m} \times 180 \mu \mathrm{m} ; 0.18$ $\mu \mathrm{m}$ RTX-5 and the secondary column $0.75 \mathrm{~m} \times 100 \mu \mathrm{m} ; 0.10 \mu \mathrm{m}$ DB-1701. The split ratio was 50:1 and the injection temperature $300^{\circ} \mathrm{C}$. The primary oven was held at $40^{\circ} \mathrm{C}$ for 4 minutes, ramped to $235{ }^{\circ} \mathrm{C}$ at $15{ }^{\circ} \mathrm{C} \mathrm{min}-1$, and the final temperature held for 4 minutes. The secondary oven was offset by $+10{ }^{\circ} \mathrm{C}$, i.e. it started at $50{ }^{\circ} \mathrm{C}$, with $15^{\circ} \mathrm{C} \mathrm{min}-1$ ramp to $245{ }^{\circ} \mathrm{C}$ with the same holding as the primary oven. The modulator was offset by $+15^{\circ} \mathrm{C}$ from the primary oven. The modulator operated from start to $598 \mathrm{~s}$ with $4 \mathrm{~s}$ modulation period, $0.7 \mathrm{~s}$ hot time, and $1.3 \mathrm{~s}$ cold time, and from $598 \mathrm{~s}$ to the end with $4 \mathrm{~s}$ modulation period, $0.85 \mathrm{~s}$ hot time, and $1.15 \mathrm{~s}$ cold time. The MS scan range was 29-350 amu with 200 spectra/s and $70 \mathrm{eV}$ energy. 
- The molecular weight distributions in the pyrolysis oil fractions were determined by gel permeation chromatography (GPC). Samples were dissolved in tetrahydrofuran (THF), filtered through $0.45 \mu \mathrm{m}$ nylon membrane syringe filters, and analyzed using an Agilent High Performance Liquid Chromatography system (HPLC) with three GPC columns (Polymer Laboratories, $300 \times 7.5 \mathrm{~mm}$ ) packed with polystyrene-divinyl benzene copolymer gel $(10 \mu \mathrm{m}$ beads) having nominal pore diameters of $10,10^{2}$, and $10^{3} \mathrm{~nm}$, respectively. The eluent was THF and the flow rate $1.0 \mathrm{~mL} \mathrm{~min}$. The sample concentration was 1 to $2 \mathrm{mg} \mathrm{mL}^{-1}$ and an injection volume of $25 \mu \mathrm{L}$ was used. The HPLC was attached to a diode array detector measuring absorbance at $260 \mathrm{~nm}$ (band width $40 \mathrm{~nm}$ ). Retention time was converted into molecular weight by applying a calibration curve established using 18 polystyrene standards of known molecular weight (range from $1 \times 10^{6}$ daltons to 580 daltons). The molecular weights calculated are not absolute molecular weights but are an approximation based on the polystyrene calibration. 


\section{Results and discussion}

\subsection{Evaluation of the oil fraction properties}

Figure 2 presents the mass distribution of the five oil fractions collected in the fractional condensation system using stem wood. About $7 \mathrm{wt} \%$ of the total recovered oil is collected at gas temperatures above $258{ }^{\circ} \mathrm{C}$ (fraction 1), $12 \mathrm{wt} \%$ between 258 and $159{ }^{\circ} \mathrm{C}$ (fraction 2) and $19 \mathrm{wt} \%$ between 159 and $73{ }^{\circ} \mathrm{C}$ (fraction 3). Fraction 4 contains about $40 \mathrm{wt} \%$ of the total recovered oil and it represents aerosols at temperatures above $73{ }^{\circ} \mathrm{C}$ while fraction 5 contains about 23 wt \% of the recovered oil, representing oil condensed at temperatures less than $73^{\circ} \mathrm{C}$. As mentioned earlier in Section 2.3 only the mass balance for stem wood is presented due to underestimation of fractions 1 to 3 when using the other feedstocks.

By optical inspection it is possible to determine the viscosity, color and homogeneity of the oil fractions. Optical microscopy images of the oil fractions produced from stem wood are shown in Figure 3. Four of the fractions are homogenous while fraction 3 is phase separated, see Figure 3 . The viscosities of the first two fractions and fraction 4 are very high (optical inspection), which indicates low water content. The viscosity of fraction 3 is somewhat lower while the viscosity of fraction 5 is much lower, comparable with water. The color of fractions 1-4 was dark brown and of fraction 5 reddish yellow with a strong acidic smell. From the optical inspection it is possible to determine that the five fractions differ significantly in viscosity, color and homogeneity independently of the feedstock used.

The chemical and physical properties of the different oil fractions produced from stem wood, forest residue and willow are collected in Tables S1-S3. The chemical composition of the oil fractions produced from the different feedstocks, received using to the solvent fractionation method, can also be seen in Figure 4. In Figure 5 the chemical groups in the fractions produced from stem wood are expressed on weighted basis. The data in Figure 5 is computed by combining the mass distribution of the respective 
fractions, Figure 2, and the concentrations of chemical groups, Figure 4, and shows how much of the specific compound group that ends up in the specific fraction. As the optical observation indicated fractions 1, 2 and 4 have low water contents, $2-6$ wt \%, while fractions 3 and 5 contain $36-42$ wt \% and $50-53$ wt \% water, respectively, see Figure 4 . The condensers separate the compounds in the oil according to their dew point, and the coalescing filters are designed to collect aerosols. Other factors, such as collector design and gas flow rates, impact the collection efficiencies but the fractions are still separated according to dew points and whether they are aerosols. Water with a relatively low dew point should be condensed at approximately $40{ }^{\circ} \mathrm{C}$ based on the current conditions. The gas temperature before and after the collection of oil fraction 3 are $156{ }^{\circ} \mathrm{C}$ and $70{ }^{\circ} \mathrm{C}$ but since the wall is cooled with water at a temperature of $4{ }^{\circ} \mathrm{C}$ some water will condense in this fraction. The high water concentrations in fraction 3, see Figure 4, also explain why this oil fraction is phase separated. The rest of the water is collected in fraction 5 , which is almost entirely water soluble and contains insignificant amounts of water insoluble material (Figure 4). About $55 \mathrm{wt} \%$ of the collected water is found in fraction 5 and about $33 \mathrm{wt}$ $\%$ in fraction 3, see Figure 5.

The water insoluble compounds, which include both LMM and HMM lignin and extractives, are foremost collected in fraction 4 but also in fractions 1 and 2 as can be seen in Figure 5 . About 64 wt \% of LMM lignin and extractives and 60 wt \% of HMM lignin are collected in fraction 4, while 33 wt \% of LMM lignin and $27 \mathrm{wt} \%$ of HMM lignin and extractives are collected in the first two fractions for stem wood. The fact that most of the water insoluble compounds are collected in fraction 4 (the coalescing filters) indicates that the water insoluble compounds are to a large degree in the form of aerosols.

Water soluble compounds, EIS (anhydrosugars, anhydrooligomers and hydroxy acids $(C<10)$ ) and ES (aldehydes, ketones, acids, alcohols and lignin monomers), can be found in high contents in all fractions, see Figure 4. However, since fraction 4 and 5 have the highest masses, most of the EIS is found in fraction 4 and ES in fractions 4 and 5 when stem wood is used as feedstock, see Figure 5. Also a large 
part of the ether insolubles seems to be in the form of aerosols since a large portion is collected in fraction 4. In the study by Rover et al. [19], a majority of the water soluble sugars was captured in the first two fractions, collected in a heat exchanger and in an electrostatic precipitator above $102{ }^{\circ} \mathrm{C}$. In order to collect the sugars in a separate fraction a more efficient cooling in the first condenser should thus be used in the setup described here. This could be achieved by decreasing the gas temperature to about $100{ }^{\circ} \mathrm{C}$, followed by a unit to collect the aerosols.

The concentrations in the respective oil fractions produced from the different feedstocks are relatively similar, see Figure 4. However, some minor differences can be seen. For example slightly higher water concentrations can be seen in oil from forest residue and willow compared to stem wood, which could be correlated to the higher alkali content. Alkali metals catalyze pyrolysis reactions and affect the formation of water during the pyrolysis [30]. Also slightly higher concentrations of water insoluble compounds are obtained in the oils produced from forest residue and stem wood compared to from willow, which can be correlated to the higher content of lignin and extractives in the forest feedstocks [25]. The results shows that the chemical composition varies to a much greater extent between the five different oil fractions than between the respective oil fractions produced from different feedstocks. In the literature most fractional condensation studies have focused on one specific feedstock and not on a variety of feedstocks. It would thus be valuable to study drastically different feedstock (such as agricultural residues) than evaluated here (forest residue, willow and stem wood) and its influence on the fractionated oil properties.

All ultimate analyses (on dry basis) of the oil fractions produced from the different feedstocks are given in Tables S1-S3. Figure 6 shows a so called Van Krevelen diagram, which illustrates the molar ratios $\mathrm{H} / \mathrm{C}$ and $\mathrm{O} / \mathrm{C}$ (on dry basis). The ratios for fractions 1,2 and 4 are rather similar. In comparison to the total collected oil, which has a $\mathrm{H} / \mathrm{C}$ ratio between 1.4 and 1.5 and an $\mathrm{O} / \mathrm{C}$ ratio between 0.52 and 0.57 , fractions 1,2 and 4 have lower $\mathrm{H} / \mathrm{C}$, i.e. contain more carbon. This is probably due to the high 
concentrations of pyrolytic lignin in these fractions, see Figure 4. The $\mathrm{H} / \mathrm{C}$ and $\mathrm{O} / \mathrm{C}$ ratios are higher in fraction 3 and even higher in fraction 5, which on the contrary can be connected to the lower amounts of pyrolytic lignin in these fractions. The $\mathrm{H} / \mathrm{C}$ and $\mathrm{O} / \mathrm{C}$ ratios of fraction 3 vary to some extent between the different feedstocks, but this could be an effect of difficulties in sampling due to the phase separation of this fraction.

In Figure 6, diagonal lines representing the hydrogen to carbon atomic effective ratio $(\mathrm{H} / \mathrm{C})_{\text {eff }}$ are also plotted. The ratio $(\mathrm{H} / \mathrm{C})_{\text {eff, }}$

$\left(\frac{H}{C}\right)_{\text {eff }}=\frac{\mathrm{H}-20}{\mathrm{C}}$

is the net molar $\mathrm{H} / \mathrm{C}$ of a compound/mixture which would theoretically be obtained after removing the oxygen content in the form of water. This ratio can be used as an index to evaluate the liquid quality for further upgrading processes [31]. Compounds with a low effective $\mathrm{H} / \mathrm{C}$ ratio, i.e. a high concentration of oxygen, cause rapid coking and deactivation of the ZSM-5 zeolite catalyst often used in catalytic vapor phase upgrading processes for lignocellulosic biomass [32]. However, in the oil fractions of the present work, the $(\mathrm{H} / \mathrm{C})_{\text {eff }}$ ratios were very similar, and the fractioning does not seem to affect the effective $\mathrm{H} / \mathrm{C}$ ratio to a high extent.

The lower heating values (LHV) of all fractions are shown in Table S1-S3. There is a large difference in LHV of the different fractions. The lowest LHV, as received, is found in fraction 5 , with a heating value of $7-8 \mathrm{MJ} \mathrm{kg}^{-1}$, while the highest is found in fractions 1,2 and 4, with a heating value from 20 to $24 \mathrm{MJ} \mathrm{kg}^{-1}$. The LHV of fraction 3 ranged between 10 and $12 \mathrm{MJ} \mathrm{kg}^{-1}$. The water content accounts for a large part of the variation in heating values but also when the heating value is based on dry matter there is a difference between the fractions. Fraction 5 still has the lowest LHV, of approximately $18 \mathrm{MJ} \mathrm{kg}^{-1}$, while fractions 1, 2 and 4 have the highest heating values $\left(21-25 \mathrm{MJ} \mathrm{kg}^{-1}\right)$ and the LHV of fraction 3 is in 
between $\left(18-20 \mathrm{MJ} \mathrm{kg}^{-1}\right)$. This can be explained by the fact that fractions 1,2 and 4 contain more energy rich compounds such as lignin-derived oligomers (water insoluble content, LMM and HMM lignin), see Figure 5. As illustrated in Figure 7, fractions 1, 2 and 4, accounting for about 59 wt $\%$ of the total bio-oil collected, represent $77 \%$ of the total energy of the pyrolysis oil collected, based on lower heating value.

The concentration of acidic constituents, measured as TAN, of all oil fractions is shown in Tables S1-S3. The acid concentration is lowest in fractions 1, 2 and 4 (42-61\%) and highest in fraction 5 (73-95\%). Most of the acid content ends up in fractions 3,4 and 5 based on mass. The acid content (TAN) in the oil produced from willow, especially in fractions 3 and 5, is somewhat higher compared to oil produced from the forest feedstocks.

The carbonyl concentrations for the stem wood pyrolysis oil fractions are included in Table S1. Carbonyl concentrations are important for evaluating the ageing tendency of oils [33] and their propensity to coke during upgrading by hydrotreating [34]. The carbonyl contents are relatively similar at $4-6 \mathrm{~mol} \mathrm{~kg}^{-1}$ in all fractions. On total mass basis, over $60 \%$ of the carbonyl functional groups are found in fractions 3 and 5. Typical carbonyls present in large quantities in pyrolysis oils are light decomposition products from the pyrolysis of the carbohydrates in biomass, e.g. hydroxyacetaldehyde and hydroxyacetone. Lignin structures also contain some ketone and aldehyde functional groups, which contribute to the carbonyls.

The results of the ${ }^{13} \mathrm{C}$ NMR analysis of the stem wood oils are summarized in Figure 8. Aliphatic C-O carbons constitute the highest single carbon type in all oils. They are particularly high in fractions 3 and 5 and correspond to $55 \%$ and $48 \%$ of all carbon, respectively. Aliphatic C-O bonds originate mainly from the carbohydrate fraction of the biomass and include carbons in anhydrosugars, alcohols (e.g. methanol) and hydroxycarbonyls (e.g. hydroxyacetaldehyde and hydroxyacetone). The levoglucosan contents were separately estimated from ${ }^{13} \mathrm{C}$ NMR data (Table S1): $16 \%$ of all carbon atoms were estimated to be in the 
form of levoglucosan in fractions 2, 3, and 4 and $12 \%$ for fraction 1 and $6 \%$ for fraction 5 . Thus levoglucosan or other similar anhydrosugars are collected over a wide range of temperatures and also in the aerosol fraction (fraction 4). Aromatic carbons (aromatic $\mathrm{C}-\mathrm{C}, \mathrm{C}-\mathrm{H}$, and $\mathrm{C}-\mathrm{O}$ ) and carbon methoxy groups are most prevalent in fractions 1,2 , and 4, see Figure 8 . This is consistent with the analysis from the solvent fractionation, which showed those fractions to be richer in lignin-derived molecules. The $\mathrm{C}=\mathrm{O}$ bonds detected by ${ }^{13} \mathrm{C}$ NMR include aldehydes, ketones, and acids. They were highest in fractions 5 (12 $\%)$ and $3(8 \%)$, in accordance with the acid and carbonyl analyses.

The ${ }^{1} \mathrm{H}$ NMR analysis of the stem wood pyrolysis oils is summarized in Figure 9. It was not possible to separate hydrogen in water, hydrogen in aromatic $\mathrm{OH}$ groups (phenols) or methoxy groups connected to aromatics, which are prevalent in lignin-derived material. These three types of protons constitute the highest fractions in all oils but in particular in fractions 5 and 3, which has high water contents. Protons connected to aromatic rings are highest in fractions 1, 2 and 4, which further confirm that these fractions have high contents of lignin-derived material.

The area counts for the most predominant peaks detected by the GC x GC - TOFMS analysis in the stem wood oils are shown in Table S4 and their mass distributions in the pyrolysis oil fractions are shown in Figure 10. It should be noted that the GC x GC-TOFMS can identify only compounds that vaporize in the GC inlet and thus is not able to identify oligomers or other high-molecular weight material. Acetic acid, hydroxypropanone (hydroxyacetone), levoglucosan, and furanone have the highest area counts. The highest acetic acid concentrations are found in fractions 5 and 3 and, of the total acetic acid mass, over $40 \%$ is found in fraction 5 (Figure 10). A comparison to total acids suggests the existence of higher molecular weight acids in fractions 4 and 3. Hydroxypropanone is concentrated in fractions 3 , 4, and 5, and furanone in fraction 4 (Figure 10). Furfural, which has uses either as a chemical or as a feedstock for other compounds, is present at the highest concentrations in fractions 3 and 5. Most of levoglucosan is found in fraction 4; it is present at similar concentrations in fraction 2 as well but that fraction is small 
and did not contribute much to the overall mass of levoglucosan. The GC x GC - TOFMS results differ somewhat from the ${ }^{13} \mathrm{C}$ NMR analysis, which suggested levels of levoglucosan to be relatively similar in

fractions 2,3 , and 4 . It is likely that the estimates from ${ }^{13} \mathrm{C}$ NMR include carbon in compounds similar to levoglucosan, i.e. other anhydrosugars and sugar oligomers. Lignin-derived molecules - 2methoxyphenol, 2-methoxy-4-methylphenol, 1,2-benzenediol and vanillin - are concentrated in fraction 4 though, similarly to levoglucosan, they are present in high concentrations also in fractions 2.

Gel permeation chromatography, GPC, was performed on the oil fractions produced from stem wood and the results can be found in Figure 11 and Table S7. The weight average molecular weight is approximately $800 \mathrm{~g} \mathrm{~mol}^{-1}$ for fraction 1 and $300 \mathrm{~g} \mathrm{~mol}^{-1}$ for fraction 5 . In general, the compounds in the fractions become lighter from fraction 1 through fraction 5 . The exception is fraction 4, the aerosol fraction, which contains more high-molecular weight material than fraction 3, as would also be expected. Fractions F1, F2, and F4 all consisted mainly of high-molecular weight compounds consistent with the other analysis results. Fraction 5 contained mainly low-molecular weight compounds and fraction 3 had features of both the high- and low-molecular weight fractions. Further optimization of the system can provide improved separation of the components.

\subsection{Discussion about possible applications}

Possible applications that have been considered for pyrolysis oil include renewable substitute for fuel oil or diesel in combustions applications, extraction of chemicals, and upgrading to transportation fuels and chemicals. As is observed in this work the different oil fractions have different chemical and physical properties and therefore the most suitable application may vary. For example, fractions 1, 2 and 4 all have low water contents, high contents of lignin-derived water insoluble components and have high heating values. These properties are favorable from a combustion point of view. Other applications for these fractions are for example to extract the pyrolytic lignin and use it to replace phenol in synthesizing 
phenol-formaldehyde resins [35] or emulsification with diesel [36]. If the water insoluble part is of interest, feedstock with high concentrations of lignin, e.g. forest feedstocks, is suitable.

The first four fractions also contain the majority of ether insoluble compounds, which include anhydrosugars, anhydrooligomers and hydroxyl acids. This chemical group includes for example levoglucosan, which according to the GC $\times$ GC - TOFMS analyses was concentrated in fraction 4 and is a major anhydrosugar product especially when cellulose rich biomass is pyrolyzed [37]. This compound is a high value product that has potentials for the manufacturing of pharmaceuticals, surfactants and biodegradable polymers [2].

The first four fractions can also be further upgraded to transportation fuels and other chemicals. The last fraction, fraction 5, contains large amount of water and compounds such as aldehydes, ketones and acids. Some of these compounds, i.e. aldehydes and acids, are unfavorable for further upgrading to transportation fuels or other chemicals [38]. Therefore it is favorable to collect these compounds in a separate fraction before the other fractions are used for further upgrading. The last fraction could instead of upgrading be used for extraction of volatile acids such as acetic acid [9] and low molecular weight aldehydes, especially glycoaldehyde (hydroxyacetaldehyde) and furfural or for production of hydrogen using steam reformation [39]. 


\section{Conclusions}

Fractional condensation of oil produced from three different feedstocks has been performed successfully. It was possible to produce oil fractions with significantly different chemical and physical properties. The first collected fractions, which condensed above $156{ }^{\circ} \mathrm{C}$, and the aerosol fraction were viscous fractions that contain larger energy-rich compounds of mainly lignin-derived material. The fraction collected between $156{ }^{\circ} \mathrm{C}$ and $70{ }^{\circ} \mathrm{C}$ contained medium-size compounds with relatively high concentration of water and sugars, alcohols, hydroxycarbonyls and acids. The last fraction, that included oil condensed below $70{ }^{\circ} \mathrm{C}$, was a nearly water soluble fraction that contained smaller molecules, such as aldehydes, ketones and acids, with high levels of water.

Possible applications of the five fractions vary from oil for combustion and extraction of the pyrolytic lignin in the early fractions, extraction of sugars from the early and middle fractions and extraction of acids and aldehydes in the later fractions. The first four fractions could also be catalytically upgraded to transportation fuels and chemicals.

The separate fractions were rather similar, even when produced from different feedstocks, which is positive since this promotes the possibility to vary the feedstocks depending on availability and still retain the oil properties.

\section{Acknowledgements}

The authors would like to thank the Swedish Energy Agency and the U.S Department of Energy under Contract No. DE-AC36-08G028308 with the National Renewable Energy Laboratory for funding this work. The authors would also want to thank Dr. Per Carlsson for initiating this project. Calle Ylipää, Mathias Lundgren, Daniel Svensson and Jimmy Narvesjö are acknowledged for invaluable technical assistance and operation of the cyclone pyrolyzer and David Johnson, Steve Deutch, Michele Myers, and Stuart Black for 
chemical analyses. Also the pulp and paper mill Smurfit Kappa Kraftliner Piteå is acknowledged for providing the bark and forest residue used in this project. 


\section{References}

[1] A. Oasmaa, E. Kuoppala and Y. Solantausta, Fast pyrolysis of forestry residue. 2. Physicochemical composition of product liquid, Energy \& fuels, 17, (2003) 433-43.

[2] S. Czernik and A.V. Bridgwater, Overview of Applications of Biomass Fast Pyrolysis Oil, Energy \& Fuels, 18, (2004) 590-98.

[3] A. Oasmaa and S. Czernik, Fuel Oil Quality of Biomass Pyrolysis OilsState of the Art for the End Users, Energy \& Fuels, 13, (1999) 914-21.

[4] S. Xiu and A. Shahbazi, Bio-oil production and upgrading research: A review, Renewable and Sustainable Energy Reviews, 16, (2012) 4406-14.

[5] A. Bridgwater, Principles and practice of biomass fast pyrolysis processes for liquids, Journal of analytical and applied pyrolysis, 51, (1999) 3-22.

[6] A.A. Lappas, S. Bezergianni and I.A. Vasalos, Production of biofuels via co-processing in conventional refining processes, Catalysis Today, 145, (2009) 55-62.

[7] J.S. Kim, Production, separation and applications of phenolic-rich bio-oil - A review, Bioresource Technology, 178, (2015) 90-98.

[8] A. Effendi, H. Gerhauser and A.V. Bridgwater, Production of renewable phenolic resins by thermochemical conversion of biomass: A review, Renewable and Sustainable Energy Reviews, 12, (2008) 2092-116.

[9] R.J.M. Westerhof, D.W.F. Brilman, M. Garcia-Perez, Z. Wang, S.R.G. Oudenhoven, W.P.M. Van Swaaij and S.R.A. Kersten, Fractional condensation of biomass pyrolysis vapors, Energy and Fuels, 25, (2011) 1817-29.

[10] D.P. Radlein, Jan; Majerski, Piotr, in, U.S., 1997.

[11] J.A. Stradal and G.L. Underwood, in, Google Patents, 1995.

[12] S.R.A. Kersten, X. Wang, W. Prins and W.P.M. van Swaaij, Biomass Pyrolysis in a Fluidized Bed Reactor. Part 1: Literature Review and Model Simulations, Industrial \& Engineering Chemistry Research, 44, (2005) 8773-85.

[13] D. Mohan, C.U. Pittman and P.H. Steele, Pyrolysis of Wood/Biomass for Bio-oil: A Critical Review, Energy \& Fuels, 20, (2006) 848-89.

[14] F. de Miguel Mercader, M.J. Groeneveld, S.R.A. Kersten, C. Geantet, G. Toussaint, N.W.J. Way, C.J. Schaverien and K.J.A. Hogendoorn, Hydrodeoxygenation of pyrolysis oil fractions: process understanding and quality assessment through co-processing in refinery units, Energy \& Environmental Science, 4, (2011) 985-97.

[15] C. Lindfors, E. Kuoppala, A. Oasmaa, Y. Solantausta and V. Arpiainen, Fractionation of Bio-Oil, Energy \& Fuels, 28, (2014) 5785-91.

[16] R.J.M. Westerhof, N.J.M. Kuipers, S.R.A. Kersten and W.P.M. van Swaaij, Controlling the Water Content of Biomass Fast Pyrolysis Oil, Industrial \& Engineering Chemistry Research, 46, (2007) 9238-47.

[17] S. Wang, Y. Gu, Q. Liu, Y. Yao, Z. Guo, Z. Luo and K. Cen, Separation of bio-oil by molecular distillation, Fuel Processing Technology, 90, (2009) 738-45.

[18] A. Tumbalam Gooty, D. Li, C. Briens and F. Berruti, Fractional condensation of bio-oil vapors produced from birch bark pyrolysis, Separation and Purification Technology, 124, (2014) 81-88.

[19] M.R. Rover, P.A. Johnston, L.E. Whitmer, R.G. Smith and R.C. Brown, The effect of pyrolysis temperature on recovery of bio-oil as distinctive stage fractions, Journal of Analytical and Applied Pyrolysis, 105, (2014) 262-68. 
[20] A.S. Pollard, M.R. Rover and R.C. Brown, Characterization of bio-oil recovered as stage fractions with unique chemical and physical properties, Journal of Analytical and Applied Pyrolysis, 93, (2012) 129-38.

[21] T. Chen, C. Deng and R. Liu, Effect of selective condensation on the characterization of bio-oil from pine sawdust fast pyrolysis using a fluidized-bed reactor, Energy and Fuels, 24, (2010) 661623.

[22] W. Hu, Q. Dang, M. Rover, R.C. Brown and M.M. Wright, Comparative techno-economic analysis of advanced biofuels, biochemicals, and hydrocarbon chemicals via the fast pyrolysis platform, Biofuels, 7, (2016) 87-103.

[23] H. Wiinikka, P. Carlsson, A.-C. Johansson, M. Gullberg, C. Ylipää, M. Lundgren and L. Sandström, Fast Pyrolysis of Stem Wood in a Pilot-Scale Cyclone Reactor, Energy \& Fuels, 29, (2015) 3158-67.

[24] J. Lédé, F. Broust, F.T. Ndiaye and M. Ferrer, Properties of bio-oils produced by biomass fast pyrolysis in a cyclone reactor, Fuel, 86, (2007) 1800-10.

[25] A.-C. Johansson, H. Wiinikka, L. Sandström, M. Marklund, O.G.W. Öhrman and J. Narvesjö, Characterization of pyrolysis products produced from different Nordic biomass types in a cyclone pilot plant, Fuel Processing Technology, 146, (2016) 9-19.

[26] L. Sandström, A.-C. Johansson, H. Wiinikka, O.G.W. Öhrman and M. Marklund, Pyrolysis of Nordic biomass types in a cyclone pilot plant - Mass balances and yields, Fuel Processing Technology, 152, (2016) 274-84.

[27] A. Oasmaa, Y. Solantausta, V. Arpiainen, E. Kuoppala and K. Sipilä, Fast pyrolysis bio-oils from wood and agricultural residues, Energy \& Fuels, 24, (2009) 1380-88.

[28] S. Black and J.R. Ferrell, III, Determination of Carbonyl Groups in Pyrolysis Bio-oils Using Potentiometric Titration: Review and Comparison of Methods, Energy and Fuels, 30, (2016) 1071-77.

[29] H. Ben and A.J. Ragauskas, NMR characterization of pyrolysis oils from kraft lignin, Energy and Fuels, 25, (2011) 2322-32.

[30] D. Mourant, Z. Wang, M. He, X.S. Wang, M. Garcia-Perez, K. Ling and C.Z. Li, Mallee wood fast pyrolysis: Effects of alkali and alkaline earth metallic species on the yield and composition of biooil, Fuel, 90, (2011) 2915-22.

[31] T.P. Vispute, H. Zhang, A. Sanna, R. Xiao and G.W. Huber, Renewable chemical commodity feedstocks from integrated catalytic processing of pyrolysis oils, Science, 330, (2010) 1222-27.

[32] N. Chen, T. Degnan and L. Koenig, Liquid fuel from carbohydrates, Chemtech, 16, (1986) 506-11.

[33] A. Oasmaa, J. Korhonen and E. Kuoppala, An approach for stability measurement of wood-based fast pyrolysis bio-oils, Energy and Fuels, 25, (2011) 3307-13.

[34] M.V. Olarte, A.H. Zacher, A.B. Padmaperuma, S.D. Burton, H.M. Job, T.L. Lemmon, M.S. Swita, L.J. Rotness, G.N. Neuenschwander, J.G. Frye and D.C. Elliott, Stabilization of Softwood-Derived Pyrolysis Oils for Continuous Bio-oil Hydroprocessing, Topics in Catalysis, 59, (2016) 55-64.

[35] S.S. Kelley, X.-M. Wang, M.D. Myers, D.K. Johnson and J.W. Scahill, in Developments in Thermochemical Biomass Conversion, Springer, 1997, p. 557-72.

[36] X.X. Jiang, J.C. Jiang, Z.P. Zhong, N. Ellis and Q. Wang, Characterisation of the mixture product of ether-soluble fraction of bio-oil (ES) and bio-diesel, The Canadian Journal of Chemical Engineering, 90, (2012) 472-82.

[37] G. Dobele, G. Rossinskaja, G. Telysheva, D. Meier, S. Radtke and O. Faix, in Progress in Thermochemical Biomass Conversion, Blackwell Science Ltd, 2008, p. 1500-08.

[38] E. Taarning, C.M. Osmundsen, X. Yang, B. Voss, S.I. Andersen and C.H. Christensen, Zeolitecatalyzed biomass conversion to fuels and chemicals, Energy \& Environmental Science, 4, (2011) 793-804. 
[39] V. Paasikallio, J. Kihlman, C.A.S. Sánchez, P. Simell, Y. Solantausta and J. Lehtonen, Steam reforming of pyrolysis oil aqueous fraction obtained by one-step fractional condensation, International Journal of Hydrogen Energy, 40, (2015) 3149-57. 


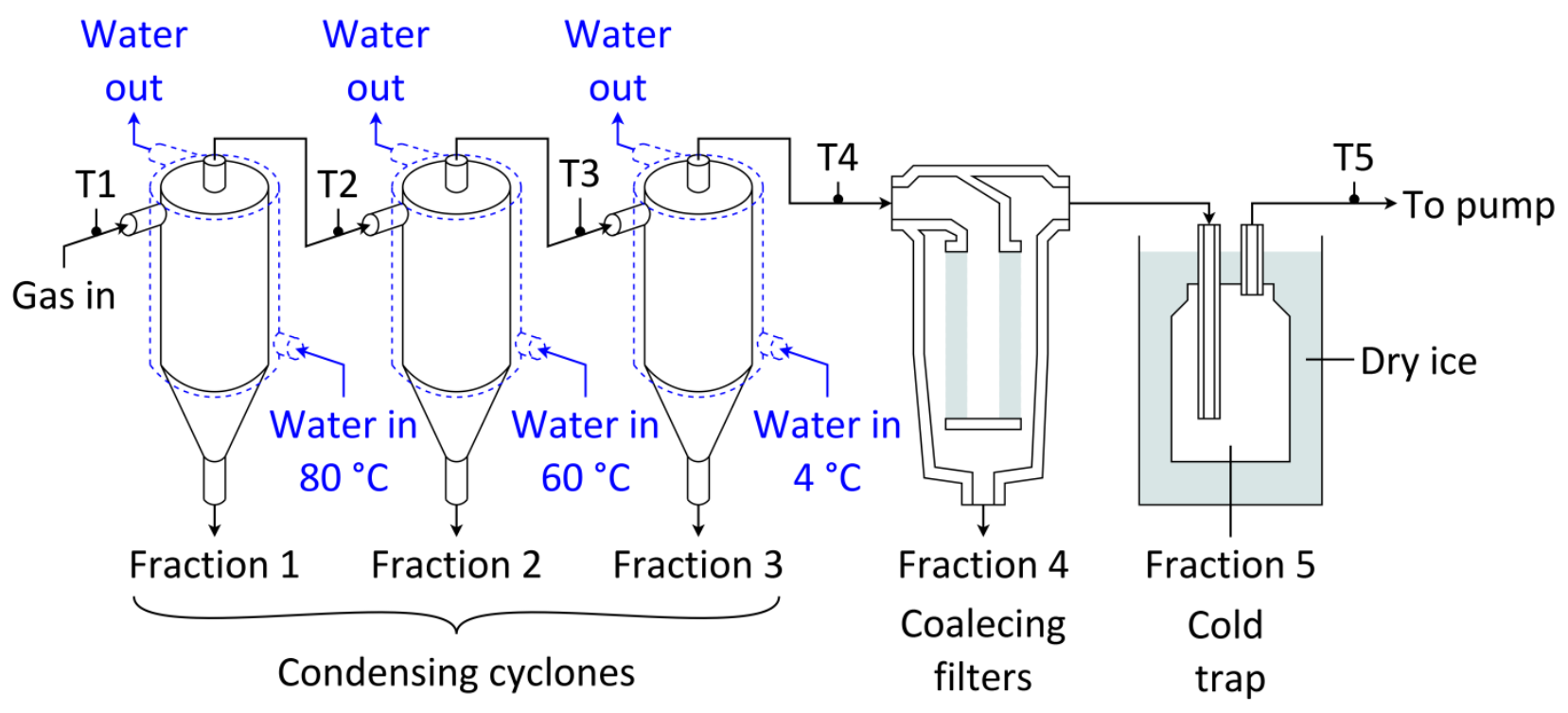

Figure 1. Schematic setup of the oil collection in the fractional condensation system. 


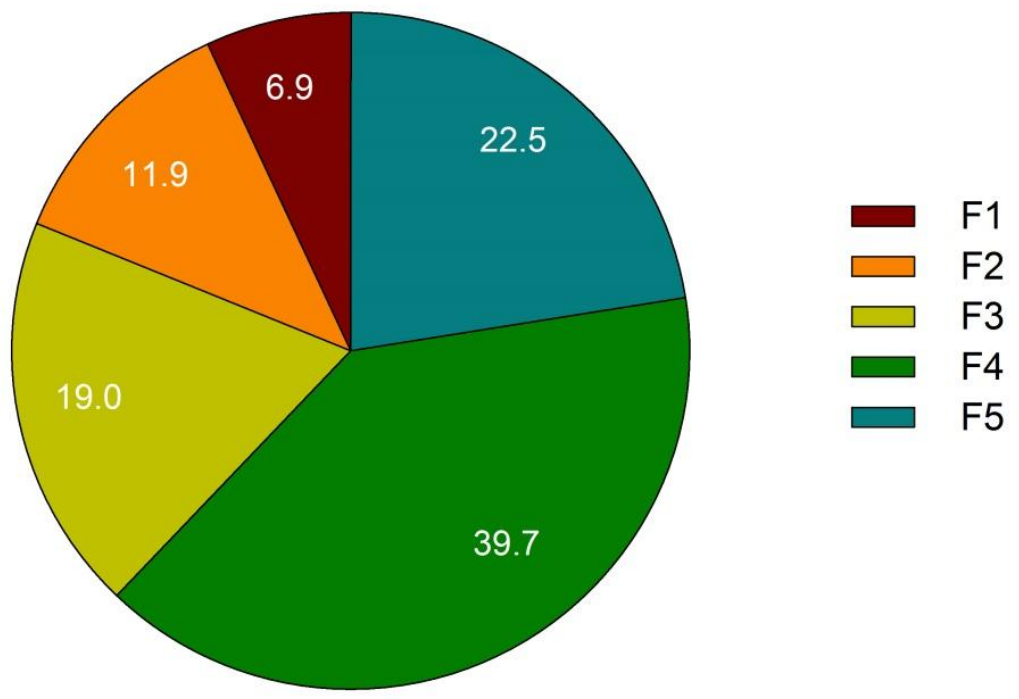

Figure 2. Mass distribution (expressed in percent) of the different fractions, F1-F5, from the fractional condensation system using stem wood as feedstock. 


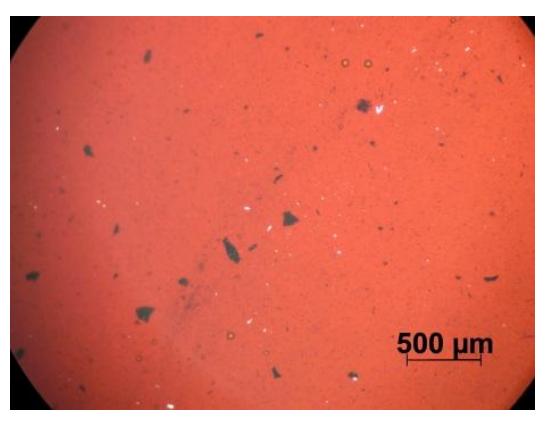

F1

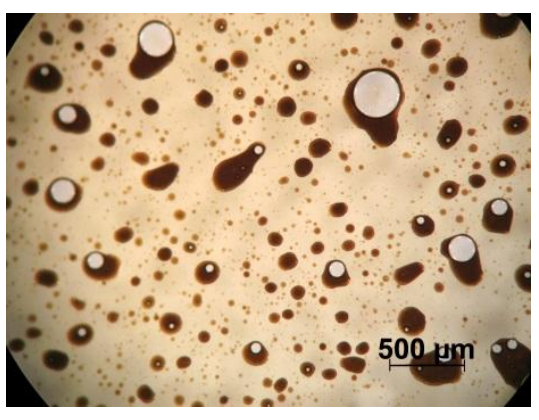

F3

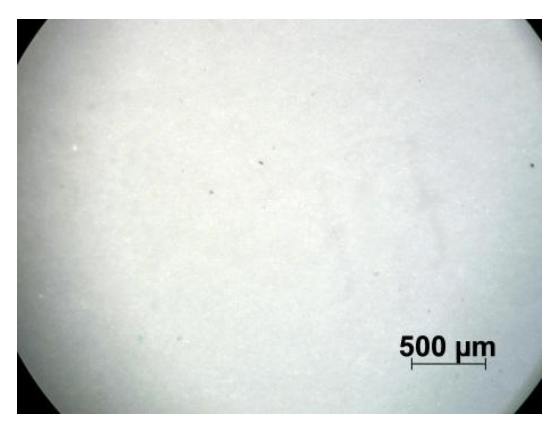

F5

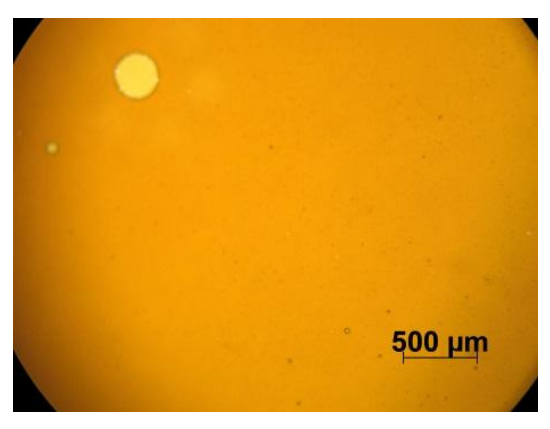

F2

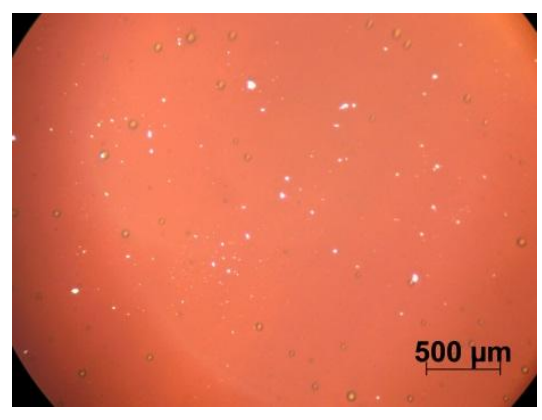

F4

Figure 3. Images of the five fractions, F1-F5, produced from stem wood collected in the fractional condensation system. 
Stem wood

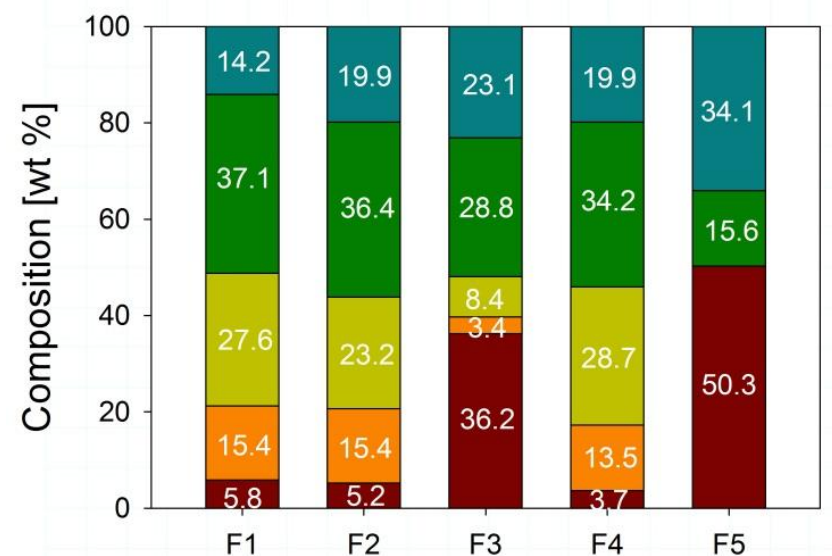

Forest residue

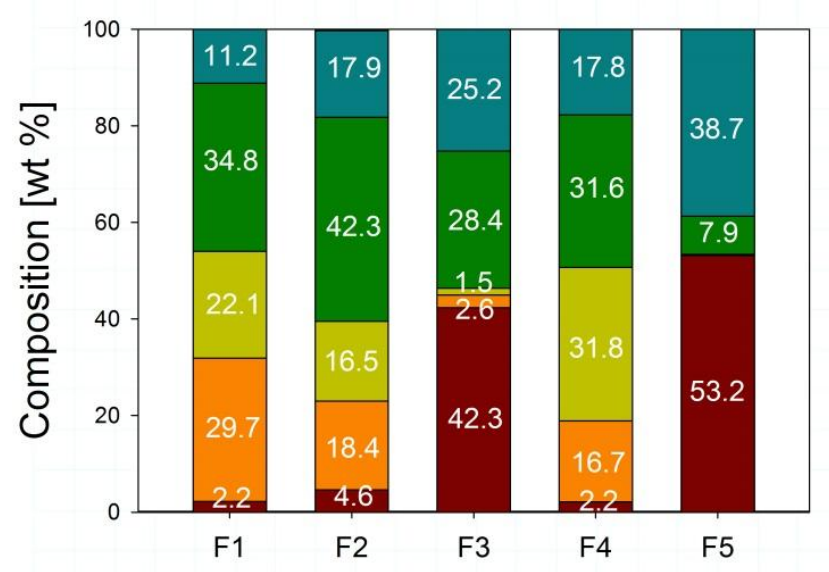

Willow

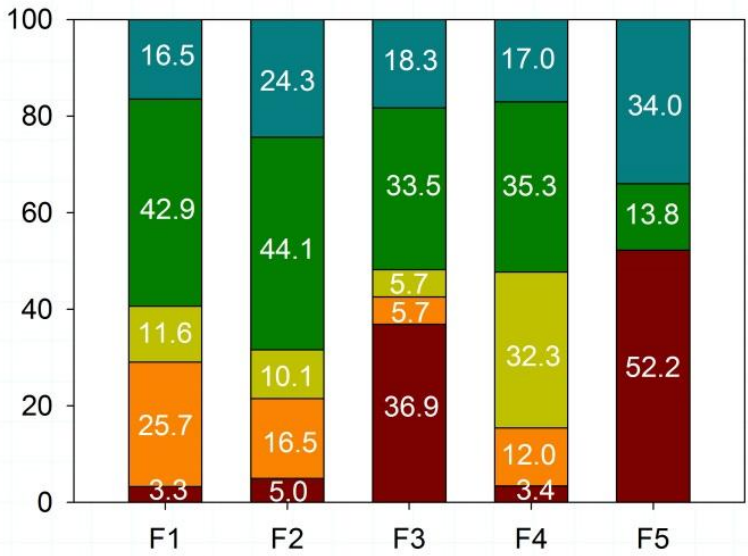

F5

Figure 4. Chemical composition, according to the solvent fractionation method, in the oil fractions, F1-F5, produced from stem wood, willow and forest residue. 


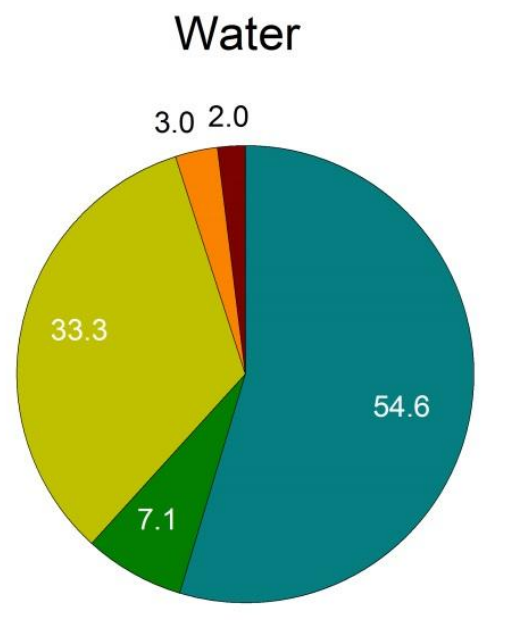

HMM lignin

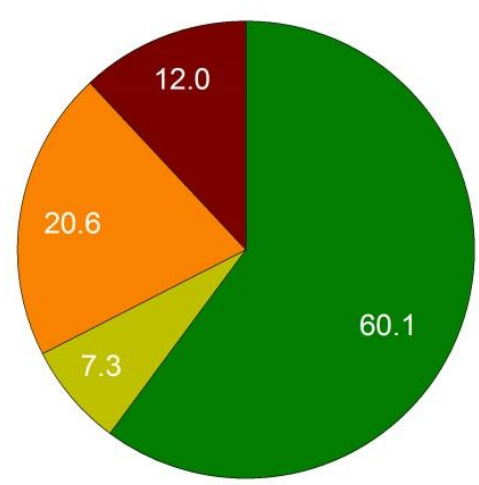

ES

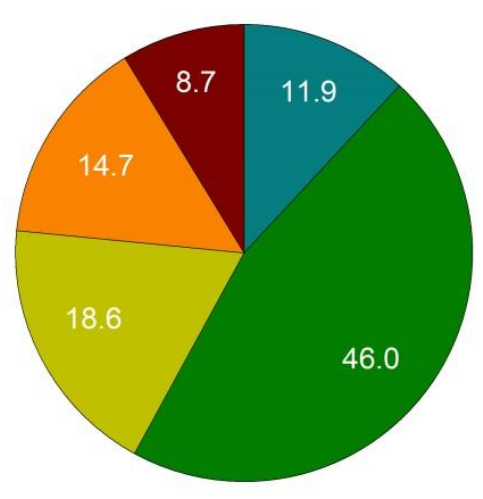

LMM lignin + extractives
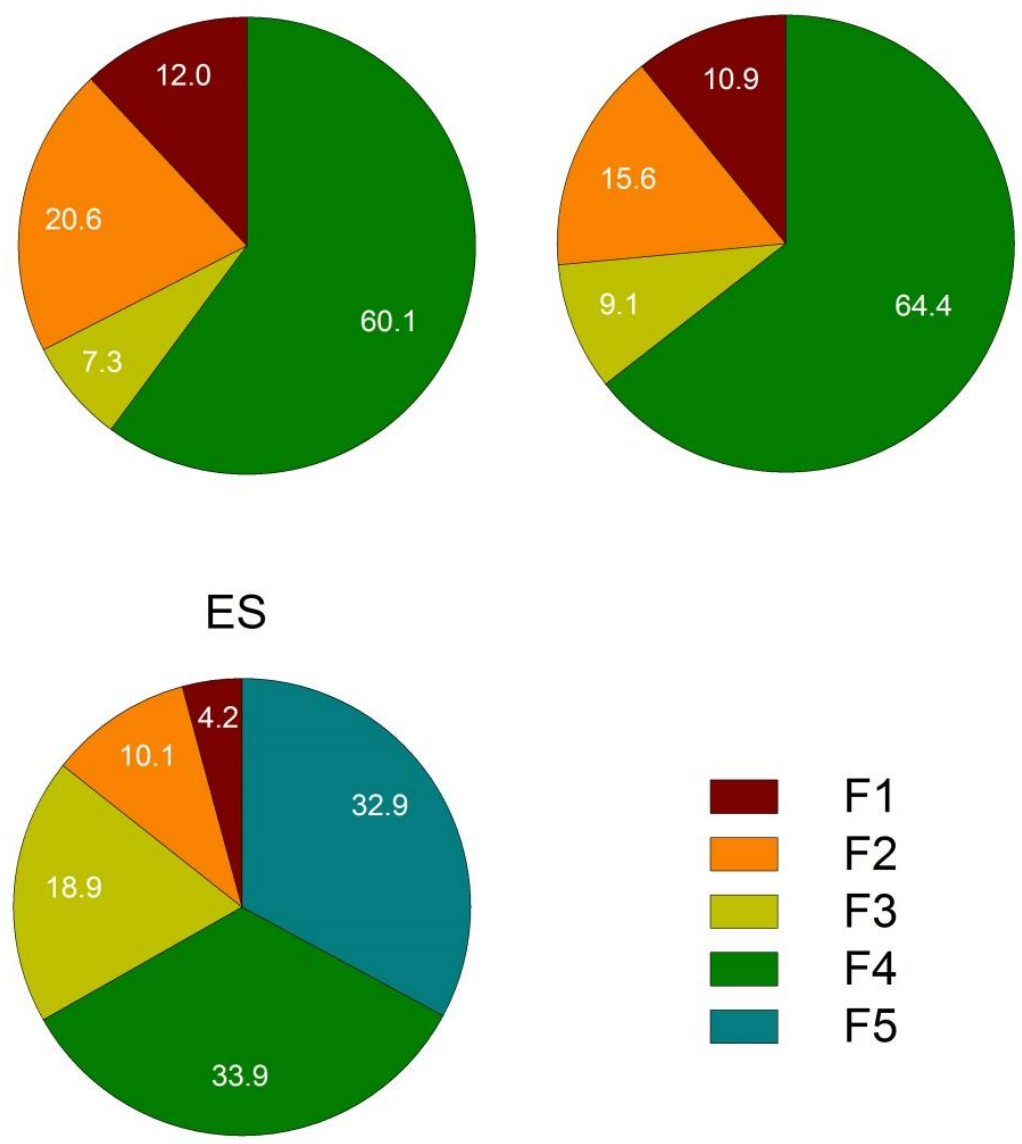

Figure 5. Mass distribution of chemical components (expressed in percent) in the five oil fractions, F1-F5, produced from stem wood based on the calculated total collected oil. 


\section{$\mathrm{H} / \mathrm{C}_{\text {eff }}$}
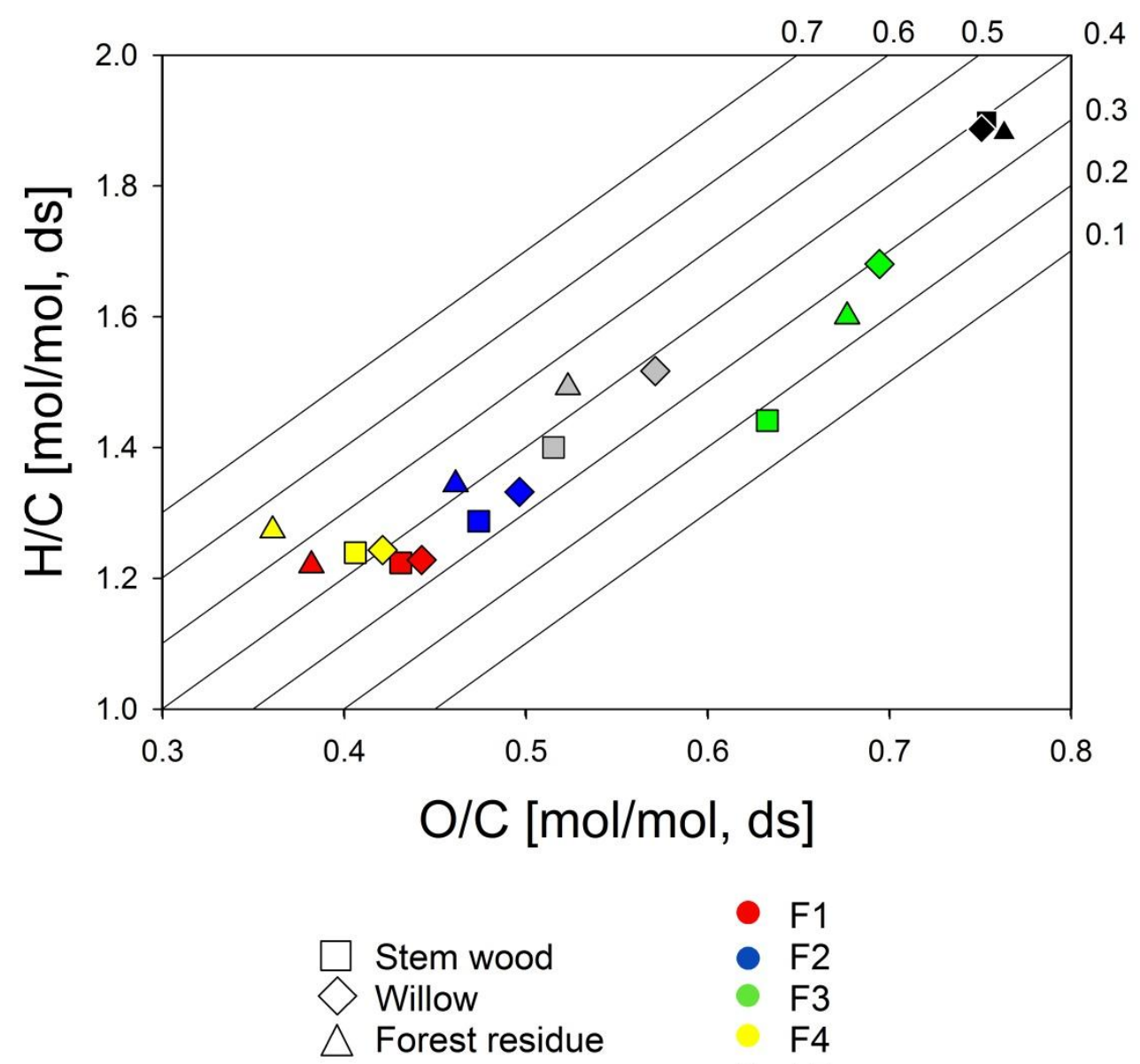

- $\mathrm{F} 1$

- $\mathrm{F} 2$

- F3

$\mathrm{F} 4$

- $\mathrm{F} 5$

Total oil

Figure 6. Van Krevelen plot for the oil fractions and total calculated oil produced from stem wood, willow and forest residue. 


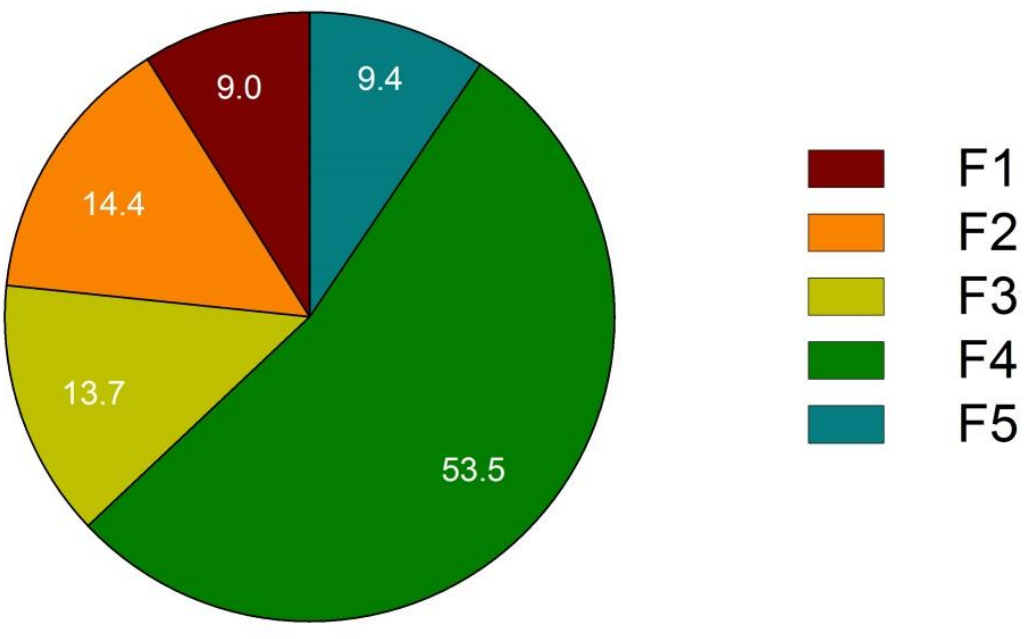

Figure 7. Distribution of energy content (expressed in percent) based on lower heating value (wet) in the five oil fractions, F1F5, produced from stem wood based on the calculated total collected oil. 


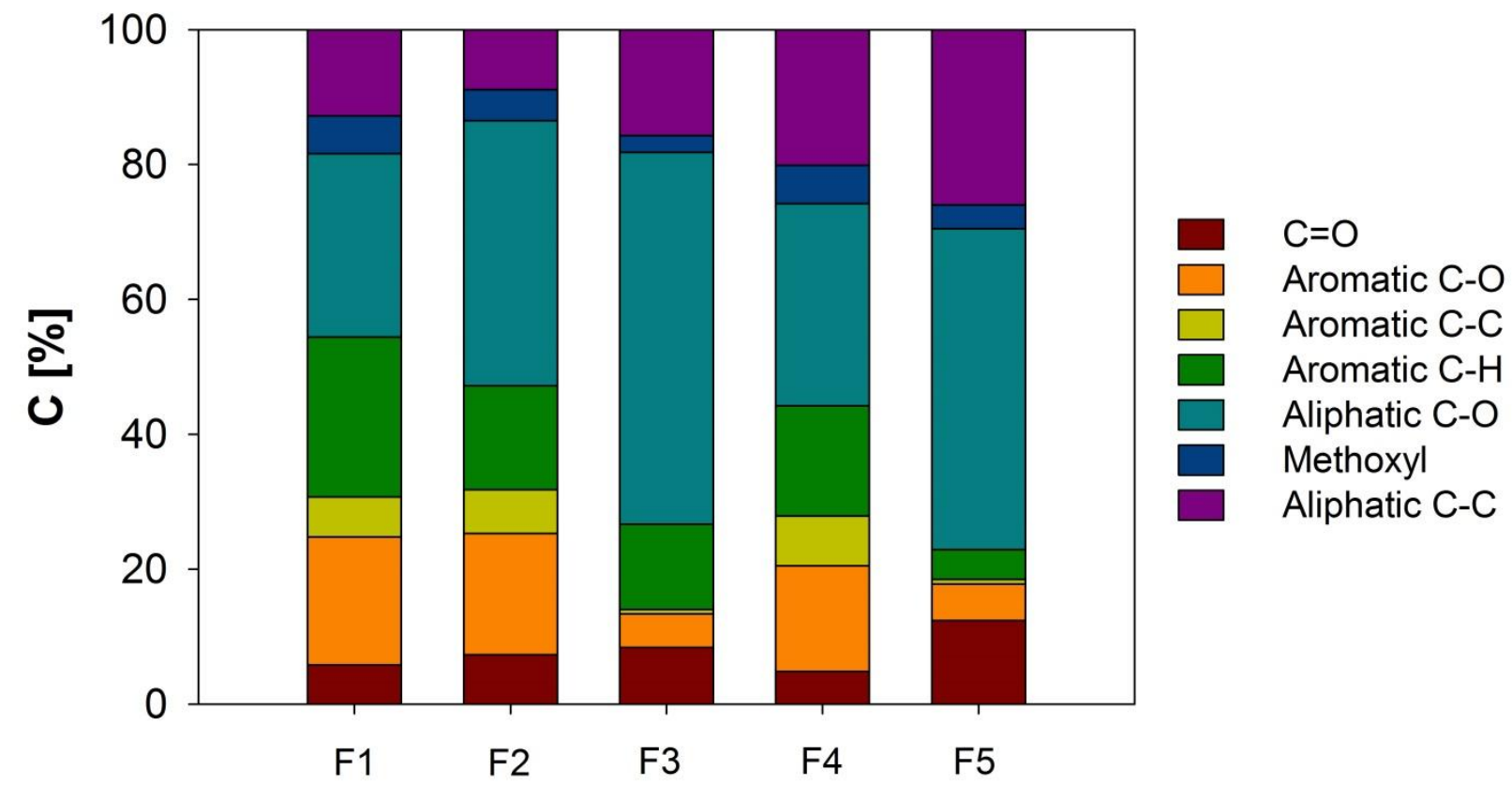

Figure $8 .{ }^{13} \mathrm{C}$ NMR analysis of the five oil fractions, F1-F5, produced from stem wood. 


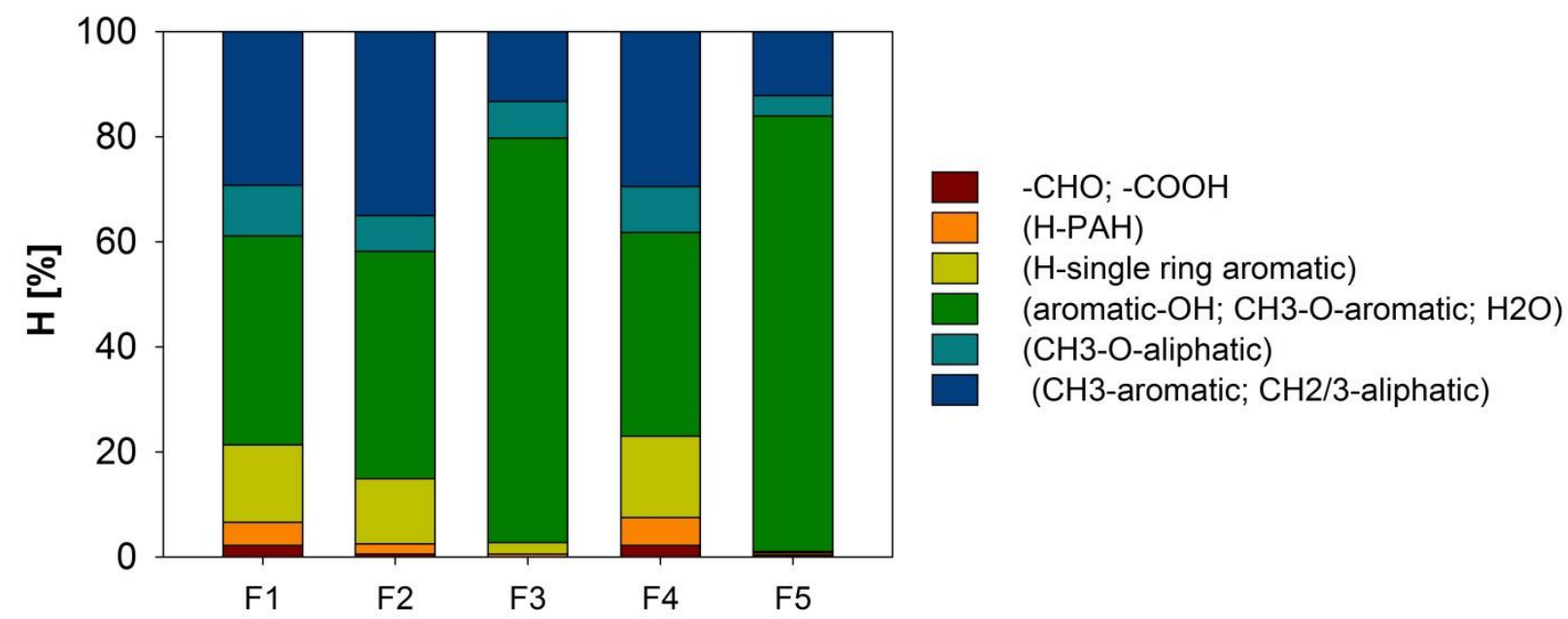

Figure 9. ${ }^{1} \mathrm{H}$ NMR analysis of the five oil fractions, F1-F5, produced from stem wood. 


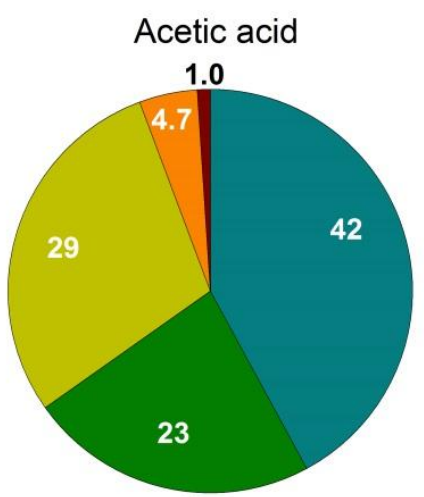

2(5H)-Furanone

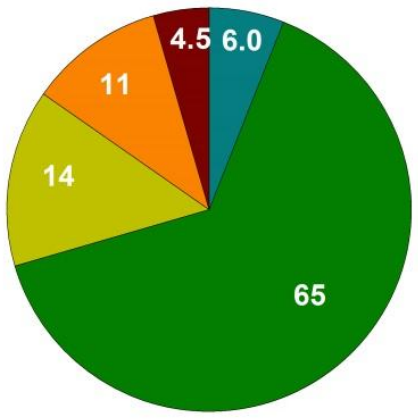

1,2-Benzenediol

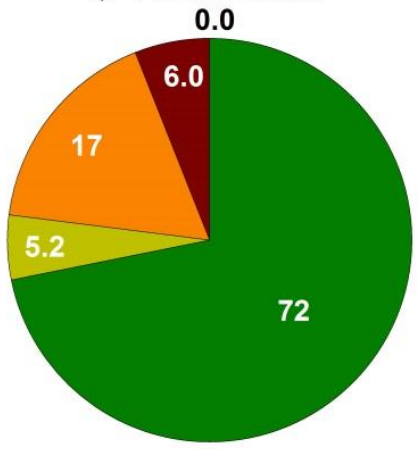

2-Propanone, 1-hydroxy-

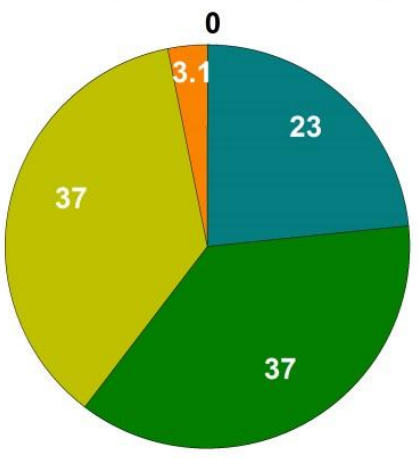

Phenol, 2-methoxy-
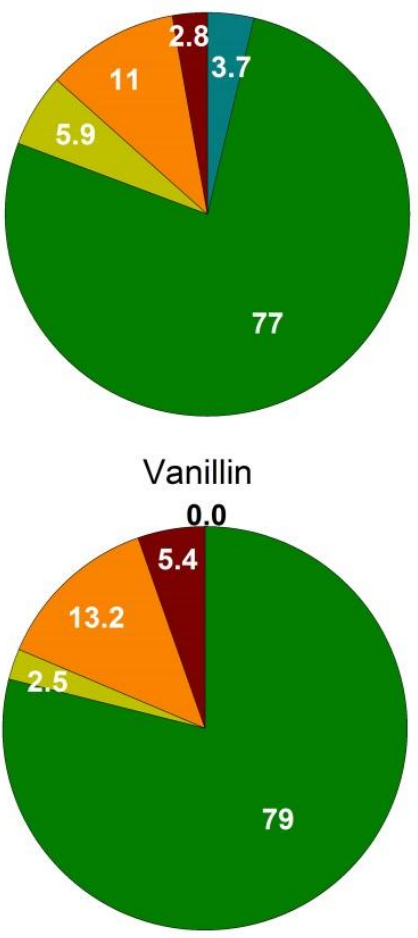

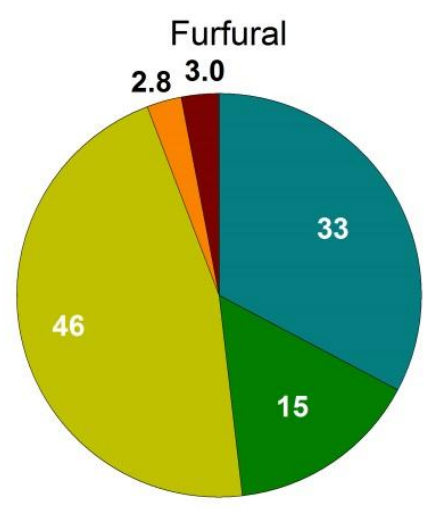

Phenol, 2-methoxy-4-methyl-
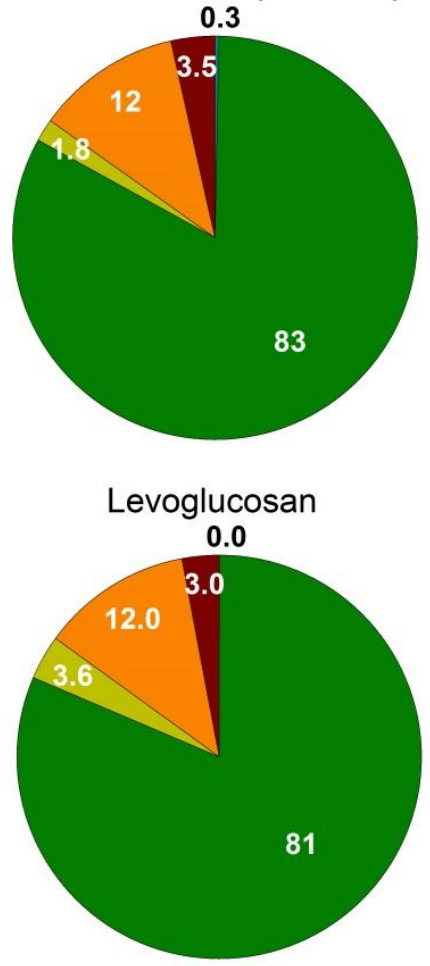

Figure 10. Distribution of nine most prominent compounds in the five oil fractions, F1-F5, (expressed in percent) produced from stem wood based on the GC $\times$ GC - TOFMS area counts and the total collected oil amounts. 


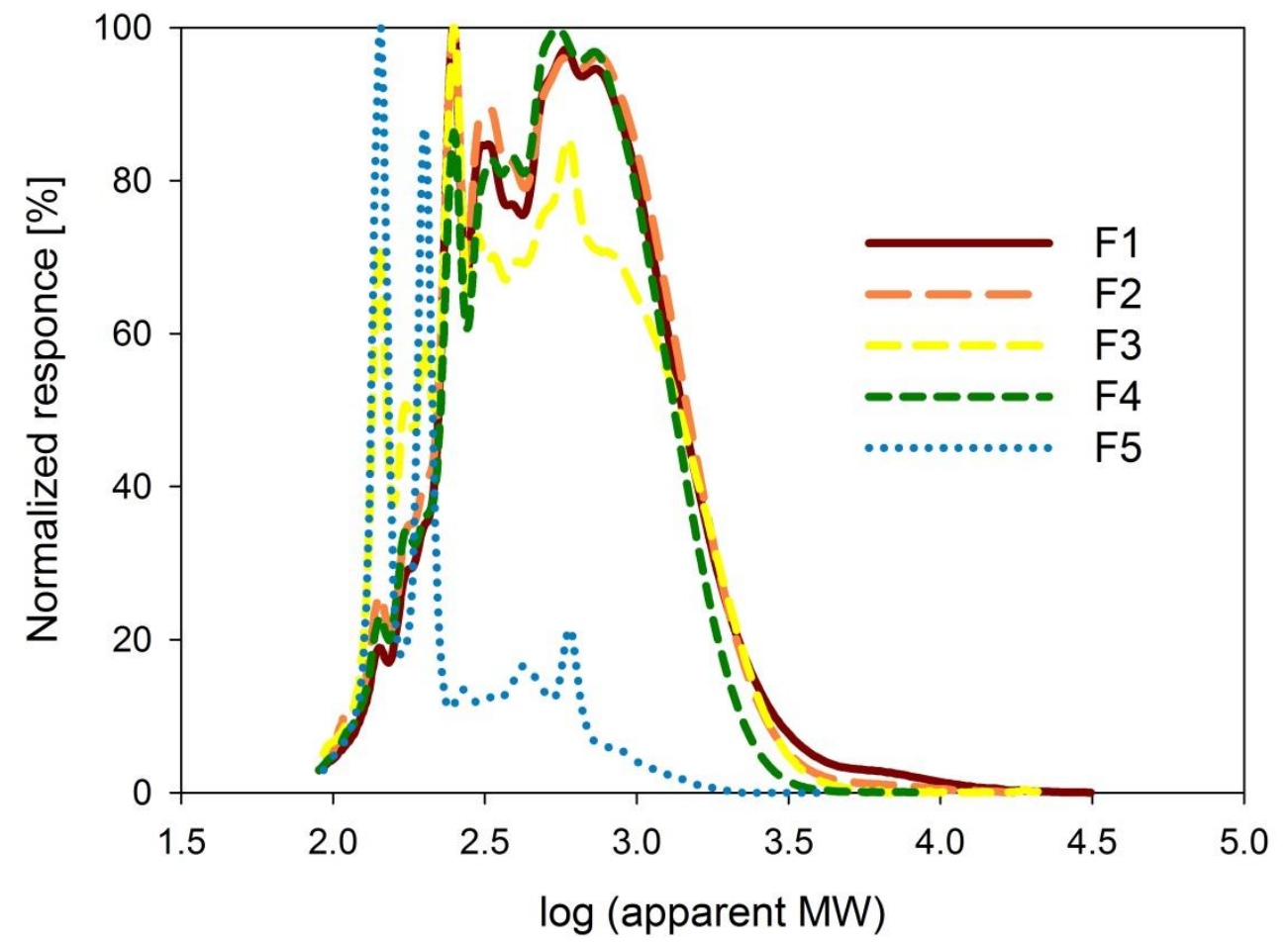

Figure 11. Molecular weight distributions for oil fractions, F1-F5, from stem wood pyrolysis. 
Table 1. Operation parameters of the cyclone pyrolyzer.

\begin{tabular}{|l|l|l|l|}
\hline Parameters & Stem wood & Forest residue & Willow \\
\hline Average feeding rate $\left[\mathrm{kg} \mathrm{h}^{-1}\right]$ & 19.5 & 21.4 & 17.8 \\
\hline Run time [min] & 180 & 99 & 156 \\
\hline Set reactor wall temperature $\left[{ }^{\circ} \mathrm{C}\right]$ & 750 & 750 & 750 \\
\hline
\end{tabular}


Table 2. Biomass Feedstock Properties

Unit

Stem wood

Forest residue

Willow

Analysis methods

\begin{tabular}{|c|c|c|c|c|c|}
\hline \multicolumn{6}{|l|}{ Proximate analysis } \\
\hline Moisture & wt $\%$, as received & 4.3 & 3.6 & 5.9 & SS 0281 13-1 \\
\hline Volatiles & wt \%, ds & 83.8 & 79.0 & 81.3 & SS-EN 15148:2009 \\
\hline $\operatorname{Ash}\left(550^{\circ} \mathrm{C}\right)$ & wt \%, ds & 0.3 & 2.4 & 1.8 & SS-EN 14775:2009/15403:2011 \\
\hline Fixed carbon & wt \%, ds & 15.9 & 19.5 & 16.9 & by difference \\
\hline \multicolumn{6}{|c|}{ Ultimate analyses, ratios and heating values } \\
\hline $\mathrm{C}$ & wt \%, ds & 51.3 & 51.9 & 49.6 & SS-EN 15104:2011/15407/15407:2011 \\
\hline H & wt \%, ds & 6.2 & 6.2 & 6.0 & \\
\hline $\mathrm{N}$ & wt \%, ds & 0.1 & 0.42 & 0.47 & \\
\hline 0 & wt \%, ds & 42 & 39.9 & 42.0 & by difference \\
\hline $\mathrm{Cl}$ & wt \%, ds & $<0.02$ & $<0.02$ & $<0.02$ & SS-EN 15289:2011/15408:2011 \\
\hline S & wt $\%$, ds & 0.021 & 0.024 & 0.041 & \\
\hline $\mathrm{O} / \mathrm{C}$ & $\mathrm{mol} / \mathrm{mol}$, ds & 0.61 & 0.58 & 0.64 & \\
\hline $\mathrm{H} / \mathrm{C}$ & $\mathrm{mol} / \mathrm{mol}$, ds & 1.44 & 1.42 & 1.44 & \\
\hline $\mathrm{H} / \mathrm{C}_{\mathrm{eff}}$ & $\mathrm{mol} / \mathrm{mol}$, ds & 0.29 & 0.27 & 0.17 & \\
\hline LHV & $\mathrm{MJ} \mathrm{kg}{ }^{-1}, \mathrm{ds}$ & 19.305 & 19.553 & 18.395 & SS-EN 14918:2010/15400:2011 \\
\hline \multicolumn{6}{|l|}{ Major inorganics } \\
\hline $\mathrm{Si}$ & wt \%, ds & 0.0067 & 0.1262 & 0.0725 & EPA method 2007.7 and 200.8 \\
\hline Al & wt \%, ds & 0.0017 & 0.0309 & 0.0150 & \\
\hline $\mathrm{Ca}$ & wt \%, ds & 0.0587 & 0.2666 & 0.4603 & \\
\hline $\mathrm{Fe}$ & wt \%, ds & 0.0003 & 0.0046 & 0.0031 & \\
\hline K & wt \%, ds & 0.0303 & 0.1494 & 0.1610 & \\
\hline $\mathrm{Mg}$ & wt \%, ds & 0.01055 & 0.0411 & 0.0335 & \\
\hline $\mathrm{Mn}$ & wt \%, ds & 0.0065 & 0.0242 & 0.0017 & \\
\hline $\mathrm{Na}$ & wt \%, ds & 0.0023 & 0.0113 & 0.0110 & \\
\hline$P$ & wt \%, ds & 0.0026 & 0.0312 & 0.0467 & \\
\hline $\mathrm{Ti}$ & $w t \%$, ds & 0.00006 & 0.0013 & 0.0007 & \\
\hline $\mathrm{Zn}$ & $w t \%, d s$ & 0.0009 & 0.005 & 0.005 & \\
\hline \multicolumn{6}{|c|}{ Chemical composition } \\
\hline Cellulose & wt \%, ds & 35.9 & 29.1 & 35.6 & SCAN-CM 71:09 \\
\hline Hemicellulose & wt \%, ds & 23.1 & 19.9 & 16.6 & \\
\hline Lignin & wt \%, ds & 27.2 & 31.2 & 25.3 & Tappi T222 \\
\hline Acetone extractives & wt \%, ds & 5.12 & 4.37 & 1.42 & SCAN-CM 49 \\
\hline
\end{tabular}


Table 3. Calculated oil yield from the pilot plants collection system and the fractional condensation system.

\begin{tabular}{|l|l|l|l|}
\hline Feedstock & Stem wood & Willow & $\begin{array}{l}\text { Forest } \\
\text { residue }\end{array}$ \\
\hline Oil yield (Pilot plant collection system) [wt \%] & 55.0 & 51.9 & 49.2 \\
\hline Oil yield (Sampling system) [wt \%] & 57.0 & 45.0 & 40.4 \\
\hline $\begin{array}{l}\text { Difference = estimate for oil trapped in } \\
\text { cyclones [wt \%] }\end{array}$ & - & 6.9 & 8.8 \\
\hline Oil trapped in the cyclones (estimate) [g] & - & 54 & 44 \\
\hline
\end{tabular}

